\title{
Death after awakening from post-anoxic coma: the "Best CPC" project
}

\author{
Fabio Silvio Taccone ${ }^{1,2^{*}}$, Janneke Horn ${ }^{3}$, Christian Storm ${ }^{4}$, Alain Cariou ${ }^{5}$, Claudio Sandroni ${ }^{6}$, Hans Friberg ${ }^{7}$, \\ Cornelia Astrid Hoedemaekers ${ }^{8}$ and Mauro Oddo ${ }^{9}$
}

\begin{abstract}
Background: In patients who recover consciousness after cardiac arrest (CA), a subsequent death from non-neurological causes may confound the assessment of long-term neurological outcome. We investigated the prevalence and causes of death after awakening (DAA) in a multicenter cohort of CA patients.

Methods: Observational multicenter cohort study on patients resuscitated from CA in eight European intensive care units (ICUs) from January 2007 to December 2014. DAA during the hospital stay was extracted retrospectively from patient medical records. Demographics, comorbidities, initial CA characteristics, concomitant therapies, prognostic tests (clinical examination, electroencephalography (EEG), somatosensory evoked potentials (SSEPS)), and cause of death were identified.

Results: From a total 4646 CA patients, 2478 (53\%) died in-hospital, of whom 196 (4.2\%; ranges 0.6-13.0\%) had DAA. DAA was less frequent among out-of-hospital than in-hospital CA (82/2997 [2.7\%] vs. 114/1649 [6.9\%]; $p<0.001)$. Median times from CA to awakening and from awakening to death were 2 [1-5] and 9 [3-18] days, respectively. The main causes of DAA were multiple organ failure $(n=61)$, cardiogenic shock $(n=61)$, and re-arrest $(n=26)$. At day 3 from admission, results from EEG $(n=56)$ and SSEPs $(n=60)$ did not indicate poor outcome.

Conclusions: In this large multicenter cohort, DAA was observed in $4.2 \%$ of non-survivors. Information on DAA is crucial since it may influence epidemiology and the design of future CA studies evaluating neuroprognostication and neuroprotection.
\end{abstract}

Keywords: Outcome, Awakening, Cardiac arrest, Prognostication

\section{Introduction}

Despite continuous medical advances, the majority of patients who are initially resuscitated from cardiac arrest (CA) and admitted to the hospital die because of irreversible hypoxic-ischemic encephalopathy (HIE) [1, 2]. As such, research has focused predominantly on the implementation of potential neuroprotective strategies, like targeted temperature management (TTM) [3], as well as on the improvement of prognostication tools to early identify those patients with severe HIE $[4,5]$.

Around one third of deaths after CA are due to nonneurological causes, such as cardiogenic shock, sepsis, or multiple organ failure (MOF). Most of these deaths occur during the first 3 days after the return of

\footnotetext{
* Correspondence: ftaccone@ulb.ac.be

${ }^{1}$ Department of Intensive Care, Hopital Erasme, Université Libre de Bruxelles (ULB), Route de Lennik, 808, 1070 Brussels, Belgium

${ }^{2}$ Université Libre de Bruxelles, Brussels, Belgium

Full list of author information is available at the end of the article
}

spontaneous circulation (ROSC), which is earlier than HIE-related deaths [1]. However, delayed deaths from non-neurological causes, i.e., after TTM is discontinued, have been described [6]. Death after awakening (DAA) from post-anoxic coma may thus be misclassified as "neurological" death, since commonly used scores to assess long-term neurological recovery do not clearly distinguish between neurological and non-neurological causes of death. In one recent study, $16 \%$ of the CA patients who eventually died after ICU admission had recovered consciousness during their ICU stay [7]. Nevertheless, neurological assessment was limited, and no specific information on the results of additional prognostic tools was provided. This lack of consistency in outcome reporting after $\mathrm{CA}$ was also underlined by the Core Outcome Set for Cardiac Arrest (COSCA) initiative, which recently refined recommendations for how

(c) The Author(s). 2019 Open Access This article is distributed under the terms of the Creative Commons Attribution 4.0 International License (http://creativecommons.org/licenses/by/4.0/), which permits unrestricted use, distribution, and reproduction in any medium, provided you give appropriate credit to the original author(s) and the source, provide a link to the Creative Commons license, and indicate if changes were made. The Creative Commons Public Domain Dedication waiver (http://creativecommons.org/publicdomain/zero/1.0/) applies to the data made available in this article, unless otherwise stated. 
and when outcomes after CA should be measured and reported [8].

Thus, we developed this project called "Best CPC" (i.e., as for Cerebral Performance Category) with the aim to assess the prevalence of DAA in CA patients before hospital discharge. Moreover, we aimed to identify the characteristics of these patients, including predictors of neurological recovery, as we hypothesized that they might show no signs of poor outcome.

\section{Methods}

\section{Study population}

We retrospectively analyzed the institutional databases of eight academic ICUs where comatose CA survivors (i.e., a Glasgow Coma Scale $<9$ at hospital admission) were admitted over the study period (January 2007 to December 2014). Among patients who died prior to hospital discharge, DAA was defined as a patient who was able to obey commands and open his/her eyes during the ICU stay but eventually died before hospital discharge for any reason, including a new neurological event. The local ethical committees in each country approved the study and waived the need for informed consent because of its retrospective nature.

\section{Patient management}

All comatose patients were treated according to local protocols. Sedation policies, the site of temperature monitoring, and the specific findings on hemodynamic or ventilator management were not collected. Blood glucose levels were kept between 110 and $150 \mathrm{mg} / \mathrm{dL}$ using continuous intravenous insulin administration. A mean arterial pressure of at least $65-70 \mathrm{mmHg}$ was maintained using volume resuscitation, dobutamine, and/or norepinephrine, whenever needed. Enteral nutrition was initiated according to local practice.

Withdrawal of life-sustaining therapies (WLST) was based on an interdisciplinary approach, involving intensivists and neurologists. Strong predictors of poor outcome were considered the bilateral absence of the N20 cortical responses to sensory evoked potentials (SSEPs) or persisting coma with poor motor response and absent brainstem reflexes at 3 days or more after CA. Less strong predictors (i.e., early status myoclonus, refractory status epilepticus, or elevated neuron-specific enolase (NSE) levels) were also considered, when available, in case of prolonged coma within a collegial agreement for WLST.

\section{Data collection}

For each patient with DAA, demographics (including age, gender) and comorbid diseases (i.e., NYHA III-IV heart disease, COPD/asthma, diabetes, chronic renal failure requiring hemodialysis, liver cirrhosis, immunosuppression, previous neurological diseases such as cerebrovascular diseases, neurodegenerative diseases, or seizures) were recorded. Cardiac arrest variables according to the Utstein style (i.e., witnessed status, bystander CPR, location, time from arrest to ROSC, cardiac vs. non-cardiac causes of CA, initial rhythm) were collected $[9,10]$. Time from arrest to neurological recovery as well as time from neurological recovery to death was recorded. Death was defined post hoc as "early" if it occurred within 9 days from arrest, according to the median time from arrest to awakening (see the "Results" section). Specific therapies during the ICU stay, including TTM $\left(32-36^{\circ} \mathrm{C}\right)$, vasopressors, inotropic agents, mechanical ventilation, renal replacement therapy (RRT), intra-aortic balloon pump counterpulsation (IABP), or extracorporeal membrane oxygenation (ECMO), were also collected. Overall ICU length of stay, the occurrence and site of infection, and presumed cause for death were reported for each patient.

Additional prognostic data, whenever available, included clinical examination (i.e., motor score of the Glasgow Coma Scale, with absent or posturing motor response defined as "poor"; absence of pupillary reflexes; myoclonus) and EEG (i.e., "highly malignant" EEG patterns [11], absence of reactivity to painful stimuli, seizures or status epilepticus) both on day 1 or at days 2-3 after arrest. EEG findings were collected from the daily report of neurologists in the medical record of each patient, and tracings were not re-analyzed. The presence of N20 cortical response of somato-sensory evoked potentials (SSEPs) was recorded as well as time from arrest to SSEPs. The highest NSE during the ICU stay was also collected. Results and timing of brain imaging (i.e., brain CT scan or magnetic resonance imaging (MRI)) were recorded.

\section{Statistical analysis}

Statistical analyses were performed using IBM SPSS Statistics 24.0 for Windows. Descriptive statistics were computed for all study variables and normal distribution was assessed using the Kolmogorov-Smirnov test. Data are presented as count (percentage) or median [25th-75th percentiles]. Comparison between subgroups (IHCA vs. OHCA) was performed using the $\chi^{2}$ test or Mann-Whitney test, as appropriate. A $p$ value $<0.05$ was considered as significant.

\section{Results}

A total of 4646 patients were admitted after successful resuscitation of a $\mathrm{CA}$ in the participating centers over the study period; of those, 2997 (64\%) were OHCA and non-survivors were 2478 (53\%). Main differences among centers are reported in Table 1.

A total of 196 (4.2\%) patients were identified among non-survivors as DAA; the proportion of these patients varied from 0.6 to $13.0 \%$ among centers. In 38 (19\%) patients, DAA occurred after ICU discharge. The 
Table 1 Main differences among participating centers. Data are presented as count (\%) or median (ranges). The percentage of DAA is calculated on the total number of CA admissions

\begin{tabular}{lllllll}
\hline & Total $(n=4646)$ & OHCA/IHCA $(n=2997 / n=1649)$ & Non-survivors $(n=2478)$ & DAA $(n=196)$ & \% of DAA & Time of awakening (days) \\
\hline Center 1 & 778 & $762 / 16$ & $515(66 \%)$ & 5 & 0.6 & $1(1-1)$ \\
Center 2 & 384 & $244 / 140$ & $207(54 \%)$ & 50 & 13.0 & $1(1-42)$ \\
Center 3 & 408 & $211 / 187$ & $235(58 \%)$ & 19 & 4.7 & $3(1-9)$ \\
Center 4 & 393 & $274 / 118$ & $237(60 \%)$ & 23 & 5.9 & $2(1-7)$ \\
Center 5 & 598 & $420 / 178$ & $284(47 \%)$ & 18 & 3.0 & $8(3-44)$ \\
Center 6 & 311 & $273 / 38$ & $148(48 \%)$ & 12 & 3.9 & $4(2-8)$ \\
Center 7 & 1510 & $743 / 767$ & $671(44 \%)$ & 45 & 3.0 & $2(1-10)$ \\
Center 8 & 275 & $70 / 205$ & $181(66 \%)$ & 24 & 8.7 & $5(1-21)$
\end{tabular}

DAA death after awakening, OHCA out-of-hospital cardiac arrest, IHCA in-hospital cardiac arrest

characteristics of the study cohort are shown in Table 2; $82(42 \%)$ patients had an OHCA. DAA was less common among OHCA than among IHCA patients (82/2997 vs. $114 / 1649 ; p<0.001)$. In the group of DAA patients after OHCA, heart failure, COPD/asthma, and the use of chronic hemodialysis, bystander CPR, and an initial non-shockable rhythm were less frequent than in the IHCA group. DAA patients from OHCA also had a longer time of ROSC, received more adrenaline, were more frequently treated with TTM, and experienced more shock than DAA patients after IHCA (Table 2).

The median time from arrest to awakening was 2 [1-5] days; a large variability in time of awakening was observed among centers (Table 1). The time from arrest to awakening was similar in OHCA and IHCA patients (3 [1-5] vs. 2 [1-5] days; $p=0.77)$. The median time from awakening to death was 9 [3-18] days (9 [1-19] in OHCA vs. 9 [3-16] days in IHCA; $p=0.90)$. The causes of death in DAA were multiple organ failure (MOF) $(n=61)$, cardiogenic shock $(n=61)$, re-arrest $(n=26)$, severe acute respiratory distress syndrome $(n=20)$, sepsis/septic shock $(n=18)$, new diagnosis or ongoing cancer $(n=5)$, mesenteric ischemia $(n=3)$, and severe bleeding or pulmonary embolism ( $n=1$ each). The distribution of different causes of death showed that cardiogenic shock and re-arrest were more frequent among early non-survivors $(n=101)$, while sepsis/ARDS were more frequent among late non-survivors (Fig. 1; $p=0.008)$. The distribution of causes of death was similar between IHCA and OHCA patients (Fig. 2).

Main findings of clinical examination and additional prognostication tools in patients with DAA are reported in Table 3. On day 1 after admission, most patients (76\%) presented a poor motor response and $38 \%$ had bilateral absence of pupillary reflexes. EEG was performed in only 30 (15\%) patients; burst-suppression or suppressed EEG tracing was found in $3(9 \%)$ patients, while most had a continuous $(n=21)$ or discontinuous $(n=6)$ background. Median NSE levels were 16 [15-27] $\mu \mathrm{g} / \mathrm{L}$, with only 1 patient exceeding $50 \mu \mathrm{g} / \mathrm{L}$. A brain CT scan was performed in 52 (26\%) patients; 2 abnormal CT findings were identified (subarachnoid hemorrhage and subdural hematoma). On day 3 after admission, clinical examination was available for 167 (85\%) patients, because of some early deaths. Thirteen $(8 \%)$ patients presented bilaterally absent pupillary reflexes. EEG was available in 56 patients, with 52 of them having a continuous and 4 of them a discontinuous background. NSE levels were 17 [14-27] $\mu \mathrm{g} / \mathrm{L}$, with only 1 patient exceeding $50 \mu \mathrm{g} / \mathrm{L}$. Somato-sensory evoked potential were performed in 60 patients after a median of $4[3,4]$ days since the cardiac arrest; none of these patients had bilaterally absent cortical N20 responses.

\section{Discussion}

The results of this multicenter study showed that $4.2 \%$ of comatose CA survivors admitted to ICU die after regaining consciousness. We also observed large variability of DAA between participating centers. Most of these patients showed signs predicting good neurological outcome during the first 3 days after admission. Re-arrest was the most common cause of DAA in the early phase after CA while ARDS and sepsis were the most common causes of death thereafter.

Several studies have reported post-arrest shock, MOF, and other non-neurological conditions as the main causes of death in about one third of OHCA patients [2, $12,13]$. Nevertheless, no specific data on the occurrence of death among patients who eventually regained consciousness after the initial anoxic injury are available. In one study evaluating two different cooling strategies after OHCA [14], Deye et al. reported that a favorable neurological outcome was observed in 113 patients at day 90 after ROSC; 16 patients (4\%), who initially had recovered neurological function, had died from non-cerebral causes at that time point. Also, Nobile et al. showed that, among 210 patients who died in the ICU after initial resuscitation from CA, 33 (16\%) of them showed signs of improved neurological function, assessed by the Glasgow Coma Scale, prior to death. 
Table 2 Characteristics of study population on admission and during the ICU stay. Data are presented as counts (percentage) or median $[\mathrm{IQRs}]$

\begin{tabular}{|c|c|c|c|}
\hline & All $(n=196)$ & $\mathrm{OHCA}(n=82)$ & IHCA $(n=114)$ \\
\hline Male, $n(\%)$ & $132(67)$ & $60(72)$ & $72(63)$ \\
\hline Age, years & $73[62-79]$ & 73 [65-79] & $73[60-79]$ \\
\hline Estimated weight, kg & 75 [70-85] & 75 [70-82] & 76 [70-89] \\
\hline \multicolumn{4}{|l|}{ Comorbidities } \\
\hline Chronic hypertension & $75(38)$ & $29(35)$ & $46(40)$ \\
\hline Diabetes & $60(31)$ & $24(29)$ & $36(32)$ \\
\hline NYHA III-IV heart failure & $27(14)$ & $6(7)$ & $21(18) *$ \\
\hline Chronic coronary artery disease & $86(44)$ & $32(39)$ & $54(47)$ \\
\hline Previous vascular neurological disease & $32(16)$ & $18(22)$ & $14(12)$ \\
\hline Liver cirrhosis & $17(9)$ & $4(5)$ & $13(11)$ \\
\hline COPD/asthma & $50(26)$ & $14(17)$ & $36(32) *$ \\
\hline Chronic hemodialysis & $30(15)$ & $7(9)$ & $23(20) *$ \\
\hline Immunosuppression & $10(5)$ & $4(5)$ & $6(5)$ \\
\hline \multicolumn{4}{|l|}{ CA characteristics } \\
\hline Time of ROSC, min & $12[6-20]$ & 17 [12-25] & $10[5-15] *$ \\
\hline Adrenaline, mg & $2[1-3]$ & $3[1-4]$ & $1[1-1] *$ \\
\hline Witnessed, $n(\%)$ & $167(85)$ & $66(80)$ & $101(89)$ \\
\hline Bystander CPR, $n$ (\%) & $147(75)$ & $52(63)$ & $95(83) *$ \\
\hline Cardiac cause, $n(\%)$ & $152(78)$ & $60(73)$ & $92(81)$ \\
\hline Non-shockable rhythm, n (\%) & $127(65)$ & $43(52)$ & $84(74) *$ \\
\hline $\mathrm{ECPR}, n(\%)$ & $15(8)$ & $5(6)$ & $10(9)$ \\
\hline \multicolumn{4}{|l|}{ After hospital admission } \\
\hline Lactate on admission, mmol/dL & $5.4[2.9-8.4]$ & $5.7[2.9-8.4]$ & $5.2[2.9-8.4]$ \\
\hline Vasopressor use, $n(\%)$ & $178(91)$ & $74(90)$ & $104(91)$ \\
\hline Dobutamine use, $n$ (\%) & $107(55)$ & $44(54)$ & $63(55)$ \\
\hline TTM, n (\%) & $117(60)$ & $66(80)$ & $51(45) *$ \\
\hline Infection, n (\%) & $89(45)$ & $36(44)$ & $53(46)$ \\
\hline Shock, $n(\%)$ & $148(76)$ & $69(84)$ & $79(69) *$ \\
\hline IABP, $n(\%)$ & $16(8)$ & $6(7)$ & $10(9)$ \\
\hline Post-ROSC ECMO, n (\%) & $13(7)$ & $3(4)$ & $10(9)$ \\
\hline RRT, $n(\%)$ & $71(36)$ & $17(21)$ & $54(47) *$ \\
\hline $\mathrm{MV}, n(\%)$ & $195(99)$ & $82(100)$ & $113(99)$ \\
\hline Bleeding, $n(\%)^{\$}$ & $48(24)$ & $16(20)$ & $32(28)$ \\
\hline ICU length of stay, days & $8[3-16]$ & $9[1-16]$ & 7 [3-15] \\
\hline
\end{tabular}

ECPR extracorporeal cardiopulmonary resuscitation, ECMO extra-corporeal membrane oxygenation, ICU intensive care unit, NYHA New York Heart Association, COPD chronic pulmonary obstructive disease, $C A$ cardiac arrest, IABP intra-aortic balloon counterpulsation, $T T M$ targeted temperature management, $R R T$ renal replacement therapy, $M V$ mechanical ventilation

${ }^{\$}$ Reduction of hemoglobin of at least $2 \mathrm{~g} / \mathrm{dL}$ over $24 \mathrm{~h}$ requiring red blood cells transfusion

${ }^{*} p<0.05$ between IHCA and OHCA

These patients presented more frequently with renal, cardiovascular, and respiratory failure than ICU survivors with good neurological function, and the authors concluded that extra-cerebral organ dysfunction may have resulted in their poor outcome [7]. Our multicenter study confirms that a proportion of non-survivors show neurological recovery prior to death before hospital discharge; this best neurological status of CA patients should be reported in all studies to better characterize the evolution of such patients, in particular if neuroprotective interventions are evaluated. In the recent COSCA recommendations on outcome reporting after CA [8], 


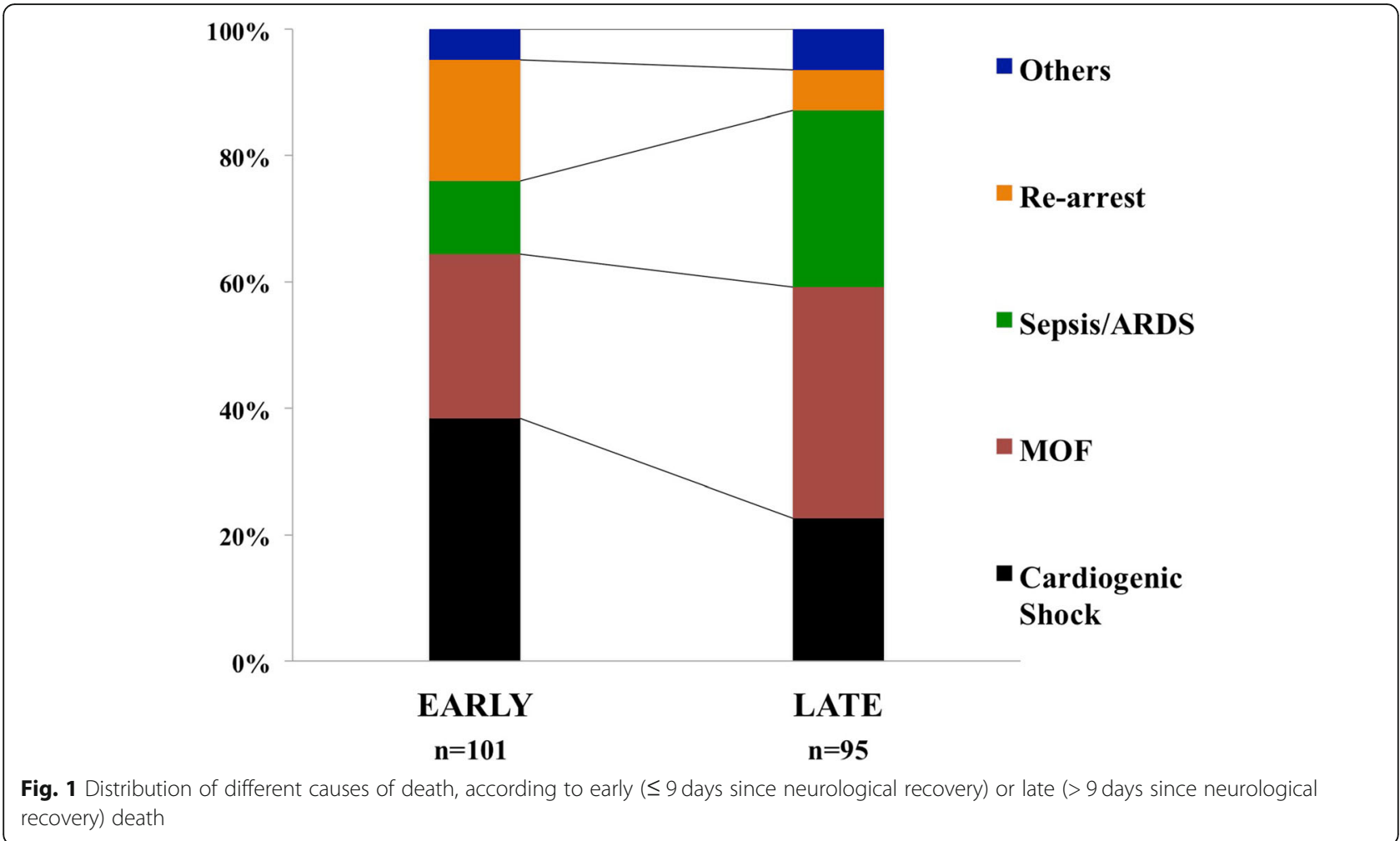

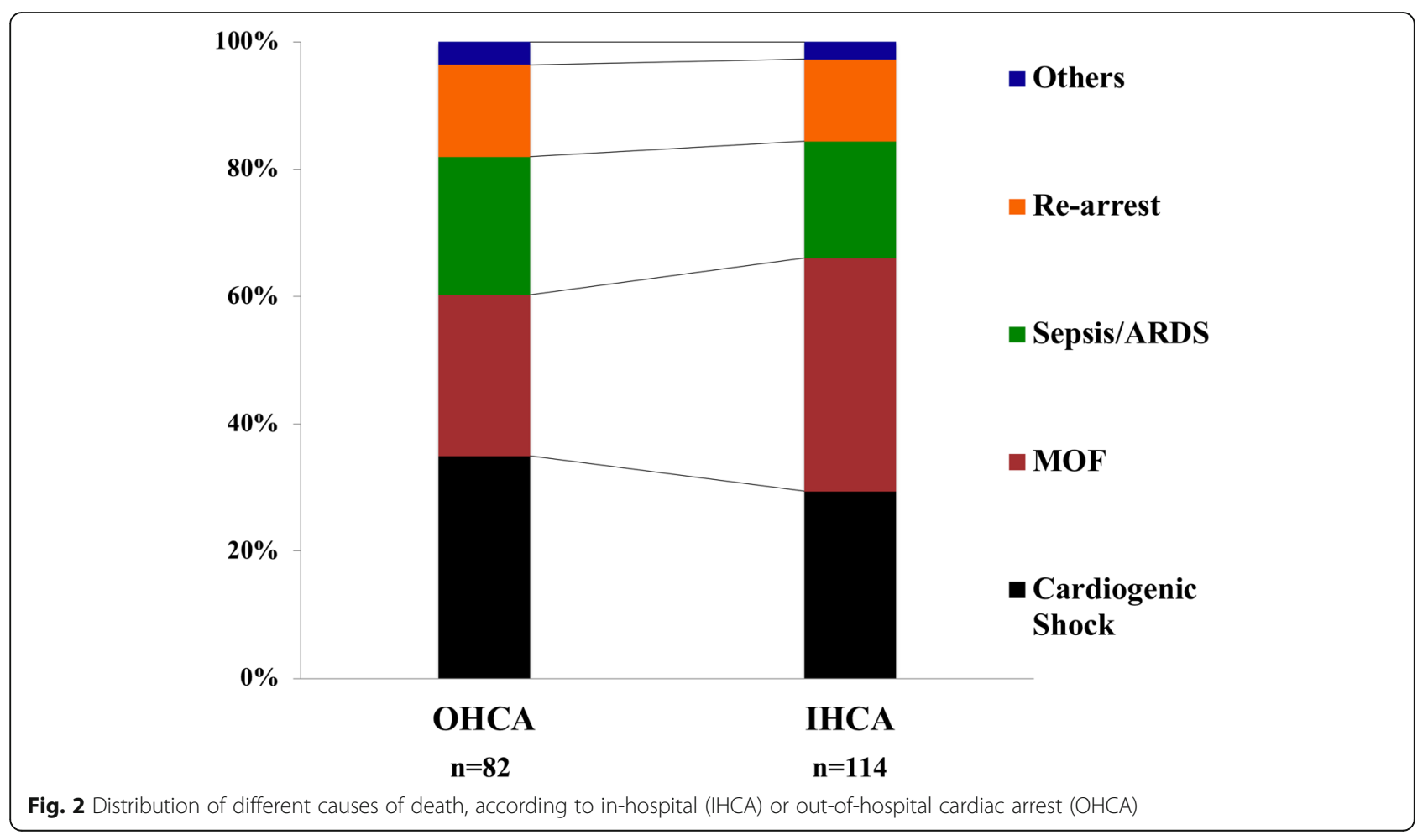


Table 3 Prognostic findings of the study cohort. Data are presented as counts (percentage) or median [IQRs]

\begin{tabular}{|c|c|c|c|c|}
\hline \multirow{3}{*}{ Motor response } & \multirow{2}{*}{\multicolumn{2}{|c|}{$\frac{\text { Day } 1}{n}$}} & \multirow{2}{*}{\multicolumn{2}{|c|}{$\frac{\text { Days 2-3 }}{n}$}} \\
\hline & & & & \\
\hline & 196 & $1[1-2]$ & 167 & $5[2-6]$ \\
\hline M1-2 MR, n (\%) & 196 & $148(76)$ & 167 & $43(26)$ \\
\hline Bilateral absent PR, $n$ (\%) & 196 & $74(38)$ & 160 & $13(8)$ \\
\hline Myoclonus, $n(\%)$ & 196 & $3(2)$ & 167 & $0(0)$ \\
\hline Clinical seizures, $n(\%)$ & 196 & $0(0)$ & 167 & $3(2)$ \\
\hline Continuous EEG, $n(\%)$ & 30 & $21(70)$ & 56 & $52(96)$ \\
\hline BS/Suppressed EEG, $n(\%)$ & 30 & $3(9)$ & 56 & $0(0)$ \\
\hline Reactive EEG, n (\%) & 26 & $22(85)$ & 44 & $40(91)$ \\
\hline NSE levels, $\mu \mathrm{g} / \mathrm{L}$ & 22 & 16 [15-27] & 37 & $17[14-27]$ \\
\hline Abnormal brain CT-scan, $n$ (\%) & 52 & $2(4)$ & 12 & $2(16)$ \\
\hline Bilaterally absent N20, n (\%) & - & - & 60 & $0(0)$ \\
\hline
\end{tabular}

M1-2 absent motor response or posturing, MR motor response, $P R$ pupillary reflexes, EEG electroencephalography, BS burst suppression, NSE neuron-specific enolase, $C T$ computed tomography, $\mathrm{N} 20$ cortical response to somato-sensory evoked potentials on the median nerve

the need for early report on survival and neurological outcome was also underlined, although no specific definition was given. We used the term of DAA, although "Best CPC" (i.e., the lowest CPC score obtained during the entire ICU and hospital stay on a daily clinical assessment) or "CPC 6" (i.e., death for all causes after regaining consciousness in contrast with CPC 5 , which would identify all non-survivors without regaining consciousness prior to death) could also be valuable alternative definitions of this finding.

Although non-cerebral causes of death have been described in earlier studies, we specifically reported their occurrence according to the timing from arrest to death. As expected, in the early phase, more than $60 \%$ of deaths were due to MOF and cardiogenic shock. Interestingly, $20 \%$ of patients with DAA died because of re-arrest. The incidence of re-arrest among patients immediately after ROSC can be as high as $80 \%$, particularly in patients with shockable rhythms in the pre-hospital setting, although this might represent a non-sustained ROSC [15]. Also, while the incidence of re-arrest has been documented in the pre-hospital setting immediately after ROSC in up to $10 \%$ of patients [16], no previous reports have described the occurrence of re-arrest after hospital admission. We do not have enough data to conclude whether re-arrest in our cohort resulted from persistent circulatory failure, coronary lesion without effective revascularization, or if it was an unexpected complication (i.e., malignant arrhythmias) in hemodynamically stable patients. Among late deaths, $55 \%$ of them were still caused by MOF and cardiogenic shock and $26 \%$ by sepsis or ARDS while 3 patients had mesenteric ischemia. Sepsis-associated CA, in particular after IHCA, is a relatively common complication, which is associated with very low survival rates [17]. CA itself is considered a "sepsis-like" syndrome with a high degree of inflammation, organ dysfunction, and microcirculatory abnormalities that can significantly contribute to post-resuscitation mortality $[18,19]$. In the TTM study, 500 out of 939 patients (53\%) developed pneumonia, severe sepsis, or septic shock, which was associated with an increased mortality in a multivariate analysis [20]. In the Intensive Care Over Nations (ICON) database, $43 \%$ of all CA patients $(n=469)$ developed an infection during the ICU stay and $28 \%$ were in septic shock [8]; in the multivariable analysis, sepsis was also an independent predictor of ICU mortality. The occurrence of ARDS is a less common event after CA; 3 to $7 \%$ of patients presented this complication in a database including 812 resuscitated patients from 1998 to 2010 [21]. Nevertheless, this low rate might be due to the stringent definition criteria used in this study, as respiratory failure has been reported in up to $50-80 \%$ of CA patients admitted to the ICU $[8,22]$. Finally, an intestinal injury is frequent after CA and is associated with the occurrence of endotoxemia, which might contribute to the worsening of post-resuscitation shock and the occurrence of organ failure [23]. However, the pathophysiology of this complication is poorly understood and its occurrence extremely rare [24]. As such, DAA occurs as the result of the ongoing disease or cardiac ischemia in the early phase after CA, while late deaths are usually due to the same causes as in non-CA ICU patients, i.e. infections and pulmonary problems. The presence of these potentially treatable causes of death, such as unexpected re-arrest, sepsis, or ARDS, underlines the importance of accurate monitoring and surveillance of CA survivors in the early phase. Future research should focus on the epidemiology of DAA in this setting, as well as the potential preventive and therapeutic measures to avoid these deaths (i.e., early coronary angiography, protective ventilation, digestive decontamination). Interestingly, in $19 \%$ of patients, DAA occurred after ICU discharge. This may suggest that those patients had shown full recovery of all acute dysfunction following CA and could be transferred to the ward; as such, DAA occurred for an unpredictable and new complication. Nevertheless, it is also possible that some limitations to an ICU re-admission could have been decided by ICU physicians; this decision may have resulted in death for a potentially treatable pathology that occurred in a patient with several comorbidities or a poor performance status.

The main impact of DAA concerns the evaluation of neuroprotective therapies and the assessment of neurological prognosis. Indeed, if a neuroprotective drug would show benefit and provide more patients recovering consciousness after the initial HIE, the assessment of neurological outcome few months after the initial event would be inadequate to demonstrate these effects, if 
patients die early from non-cerebral causes. Thus, DAA is a relevant "early" outcome to be reported together with long-term neurological outcome, quality of life, and cognitive function among CA survivors $[8,25]$. In addition, if not properly addressed, DAA may cause false-positive results and reduce the prognostic accuracy of outcome predictors after CA [26-28]. We consider that future studies on prognostication tools and strategies should report the occurrence of DAA and exclude those patients who die in the very early phase after admission without a neurological examination, as they represent a source of potential bias for the interpretation of these results.

Some limitations of our study deserve discussion. First, the retrospective design might have produced an underestimation of DAA in these patients. Prospective, specifically designed studies will be needed to address this potential bias. However, should this be the case, it would mean that the incidence of DAA is even higher than that we observed in our study. Second, large variability in the description of DAA was observed; no specific analysis of factors associated with such variability was performed because of the lack of several confounders. This variability might be related to local medical practice (i.e., use of long-term sedatives might delay awakening and promote inappropriate WLST), limitations of care procedures (i.e., different timing for WLST might influence the possibility that some patients eventually awake later), or medical files quality. Third, awakening and obeying commands cannot be entirely considered as a "good neurologic outcome"; some patients with a CPC of 3 (i.e., conscious with severe cerebral disability) might present with the same definition used for DAA and still are categorized as "poor neurologic outcome" in all studies. Fourth, we did not collect data on non-survivors due to severe HIE or on survivors; these data might have provided additional comparisons on the reasons of death, time of death, and prognostication tools among groups. Fifth, prognostic indices were available only for a small proportion of these patients. This occurred because prognostication was not systematically performed in some participating ICUs and also because some patients awakened before prognostication, i.e., within the first 1-2 days after ROSC. Sixth, only the main cause of death was reported and no information on withdrawal or limitation of life-sustaining therapies decisions was collected. Also, we missed the clinical information on the pre-arrest condition of the patients, such as the Charlson comorbidity index, in particular for IHCA patients; this information might have influenced restrictions of life-sustaining therapies in some patients. The lack of specific ICU scores, such as the Acute Physiology And Chronic Health Evaluation (APACHE) II or Sequential Organ Failure Assessment (SOFA) scores, although not validated in the CA population, might also have been interesting to further characterize the severity of the study population. Seventh, the definition of "early" and "late" deaths was arbitrary and based on the median number of days from awakening to death and could not correspond to a clinically relevant time point. Finally, the lack of additional data on hemodynamics and ventilatory management limited further analyses on predictors of death and quality of care provided to such patients.

\section{Conclusions}

$4.2 \%$ of CA survivors admitted to ICU eventually die after regaining consciousness. This phenomenon has a large variability between reporting sites. These findings should be reported in neuroprognostication studies and may be helpful for the design of future trials assessing neuroprotective interventions.

\section{Abbreviations}

ARDS: Acute respiratory distress syndrome; CA: Cardiac arrest: CPR: Cardiopulmonary resuscitation; DAA: Death after awakening; ECMO: Extracorporeal membrane oxygenation; EEG: Electroencephalography; HIE: Hypoxic ischemic encephalopathy; ICON: Intensive Care Over Nations; ICU: Intensive care unit; IHCA: In-hospital cardiac arrest; MOF: Multiple organ failure; MRI: Magnetic resonance imaging; NSE: Neuron-specific enolase; OHCA: Out-of-hospital cardiac arrest; ROSC: Return of spontaneous circulation; RRT: Renal replacement therapy; SOFA: Sequential Organ Failure Assessment; SSEP: Somato-sensory evoked potentials; TTM: Targeted temperature management

\section{Acknowledgements}

Marzia Savi, Riccardo Maviglia, Ottavia Bond, Federica Zama Cavicchi, Fredrik Strand for their help in data retrieval.

\section{Take-home message}

This study shows that $4.2 \%$ of cardiac arrest patients regain consciousness before ultimately dying of non-neurological causes. These findings suggest the need to report this "Best CPC" in the early phase after the anoxic injury to better understand the results of neuroprotective strategies and assess accuracy of prognostic tools.

\section{Tweet}

More than $4 \%$ of comatose patients after cardiac arrest awaken before dying from other causes before hospital discharge.

Funding

No funding was received for this study.

\section{Availability of data and materials}

The datasets used and/or analysed during the current study are available from the corresponding author on reasonable request.

\section{Authors' contributions}

FST and MO conceived the study protocol. All the authors collected the data in their own center. FST and MO analyzed the data. FST, CS, and MO drafted the present manuscript. All authors read and approved the final manuscript.

\section{Ethics approval and consent to participate}

The study protocol was approved by local Ethics Committees and informed consent was obtained from the patient or her/his legal representative.

Consent for publication

Not applicable.

Competing interests

The authors declare that they have no competing interests. 


\section{Publisher's Note}

Springer Nature remains neutral with regard to jurisdictional claims in published maps and institutional affiliations.

\section{Author details}

'Department of Intensive Care, Hopital Erasme, Université Libre de Bruxelles (ULB), Route de Lennik, 808, 1070 Brussels, Belgium. ${ }^{2}$ Université Libre de Bruxelles, Brussels, Belgium. 를 University of Amsterdam, Amsterdam, The Netherlands. ${ }^{4}$ Medical Department, Division of Nephrology and Internal Intensive Care Medicine, Charité-Universitätsmedizin Berlin, Berlin, Germany. ${ }^{5}$ Intensive Care Unit, AP-HP, Cochin Hospital, Descartes University, Paris, France. ${ }^{6}$ Department of Anaesthesiology and Intensive Care - Fondazione Policlinico Universitario Agostino Gemelli, Università Cattolica del Sacro Cuore, Rome, Italy. ${ }^{7}$ Department of Anesthesiology and Intensive Care Medicine, Department of Clinical Sciences, Skåne University Hospital, Lund University, Lund, Sweden. ${ }^{8}$ Department of Intensive Care, Radboud University Nijmegen Medical Centre, Nijmegen, Netherlands. 'Department of Intensive Care Medicine, Centre Hospitalier Universitaire Vaudois (CHUV), University of Lausanne, Lausanne, Switzerland.

Received: 30 October 2018 Accepted: 22 March 2019

Published online: 03 April 2019

\section{References}

1. Lemiale V, Dumas F, Mongardon N, Giovanetti O, Charpentier J, Chiche JD, et al. Intensive care unit mortality after cardiac arrest: the relative contribution of shock and brain injury in a large cohort. Intensive Care Med. 2013;39(11):1972-80

2. Dragancea I, Rundgren M, Englund E, Friberg H, Cronberg T. The influence of induced hypothermia and delayed prognostication on the mode of death after cardiac arrest. Resuscitation. 2013;84(3):337-42.

3. Tortorici MA, Kochanek PM, Poloyac SM. Effects of hypothermia on drug disposition, metabolism, and response: a focus of hypothermia-mediated alterations on the cytochrome P450 enzyme system. Crit Care Med. 2007; 35(9):2196-204.

4. Rossetti AO, Rabinstein AA, Oddo M. Neurological prognostication of outcome in patients in coma after cardiac arrest. Lancet Neurol. 2016;15(6):597-609.

5. Sandroni C, Cariou A, Cavallaro F, Cronberg T, Friberg H, Hoedemaekers C, et al. Prognostication in comatose survivors of cardiac arrest: an advisory statement from the European Resuscitation Council and the European Society of Intensive Care Medicine. Intensive Care Med. 2014;40(12):1816-31.

6. Paul M, Bougouin W, Geri G, Dumas F, Champigneulle B, Legriel S, et al. Delayed awakening after cardiac arrest: prevalence and risk factors in the Parisian registry. Intensive Care Med. 2016;42(7):1128-36.

7. Nobile L, Taccone FS, Szakmany T, Sakr Y, Jakob SM, Pellis T, et al. The impact of extracerebral organ failure on outcome of patients after cardiac arrest: an observational study from the ICON database. Crit Care. 2016;20(1):368.

8. Haywood K, Whitehead L, Nadkarni VM, Achana F, Beesems S, Böttiger BW et al. COSCA (Core Outcome Set for Cardiac Arrest) in adults: an advisory statement from the International Liaison Committee on Resuscitation. Circulation. 2018;137(22):e783-801.

9. Cummins RO, Chamberlain D, Hazinski MF, Nadkarni V, Kloeck W, Kramer E, et al: Recommended guidelines for reviewing, reporting, and conducting research on in-hospital resuscitation: the in-hospital 'Utstein style'. American Heart Association. Circulation 1997; 95(8):2213-2239.

10. Perkins GD, Jacobs IG, Nadkarni VM, Berg RA, Bhanji F, Biarent D, et al. Cardiac arrest and cardiopulmonary resuscitation outcome reports: update of the Utstein Resuscitation Registry Templates for Out-of-Hospital Cardiac Arrest: a statement for healthcare professionals from a task force of the International Liaison Committee on Resuscitation (American Heart Association, European Resuscitation Council, Australian and New Zealand Council on Resuscitation, Heart and Stroke Foundation of Canada, InterAmerican Heart Foundation, Resuscitation Council of Southern Africa, Resuscitation Council of Asia); and the American Heart Association Emergency Cardiovascular Care Committee and the Council on Cardiopulmonary, Critical Care, Perioperative and Resuscitation. Circulation. 2015;132(13):1286-300

11. Westhall E, Rossetti AO, van Rootselaar AF, Wesenberg Kjaer T, Horn J, Ullén $\mathrm{S}$, et al. Standardized EEG interpretation accurately predicts prognosis after cardiac arrest. Neurology. 2016;86(16):1482-90.
12. Laver S, Farrow C, Turner D, Nolan J. Mode of death after admission to an intensive care unit following cardiac arrest. Intensive Care Med. 2004;30:2126-8.

13. Dragancea I, Horn J, Kuiper M, Friberg H, Ullén S, Wetterslev J, et al. Neurological prognostication after cardiac arrest and targeted temperature management $33^{\circ} \mathrm{C}$ versus $36^{\circ} \mathrm{C}$ : results from a randomised controlled clinical trial. Resuscitation. 2015;93:164-70.

14. Deye N, Cariou A, Girardie P, Pichon N, Megarbane B, Midez P, et al. Clinical and Economical Impact of Endovascular Cooling in the Management of Cardiac Arrest (ICEREA) Study Group. Endovascular versus external targeted temperature management for patients with out-of-hospital cardiac arrest: a randomized, controlled study. Circulation. 2015;132(3):182-93.

15. Weaver WD, Cobb LA, Copass MK, Hallstrom AP. Ventricular defibrillation - a comparative trial using 175-J and 320-J shocks. N Engl J Med. 1982;307:1101-6.

16. Lerner EB, O'Connell M, Pirrallo RG. Rearrest after prehospital resuscitation. Prehosp Emerg Care. 2011;15(1):50-4.

17. Koivikko P, Arola O, Inkinen O, Tallgren M. One-year survival after in-hospital cardiac arrest- does pre-arrest sepsis matter? Shock. 2018:50(1):38-43.

18. Bro-Jeppesen J, Kjaergaard J, Wanscher M, Nielsen N, Friberg H, Bjerre M, et al. Systemic inflammatory response and potential prognostic implications after out-of-hospital cardiac arrest: a substudy of the target temperature management trial. Crit Care Med. 2015;43(6):1223-32.

19. Donadello K, Favory R, Salgado-Ribeiro D, Vincent JL, Gottin L, Scolletta S, et al. Sublingual and muscular microcirculatory alterations after cardiac arrest: a pilot study. Resuscitation. 2011;82(6):690-5.

20. Dankiewicz J, Nielsen N, Linder A, Kuiper M, Wise MP, Cronberg T, et al. Infectious complications after out-of-hospital cardiac arrest - a comparison between two target temperatures. Resuscitation. 2017;113:70-6.

21. Sutherasan $\mathrm{Y}$, Peñuelas $\mathrm{O}$, Muriel $\mathrm{A}$, Vargas $\mathrm{M}$, Frutos-Vivar $\mathrm{F}$, Brunetti I, et al. Management and outcome of mechanically ventilated patients after cardiac arrest. Crit Care. 2015;19:215.

22. Roberts BW, Kilgannon JH, Chansky ME, Mittal N, Wooden J, Parrillo JE, et al. Multiple organ dysfunction after return of spontaneous circulation in postcardiac arrest syndrome. Crit Care Med. 2013;41(6):1492-501.

23. Grimaldi D, Guivarch E, Neveux N, Fichet J, Pène F, Marx JS, et al. Markers of intestinal injury are associated with endotoxemia in successfully resuscitated patients. Resuscitation. 2013;84(1):60-5.

24. Wurm $R$, Cho A, Arfsten $H$, van Tulder $R$, Wallmüller $C$, Steininger $P$, et al. Non-occlusive mesenteric ischaemia in out of hospital cardiac arrest survivors. Eur Heart J Acute Cardiovasc Care. 2018;7(5):450-8.

25. Cronberg T, Lilja G, Horn J, Kjaergaard J, Wise MP, Pellis T, et al. Neurologic function and health-related quality of life in patients following targeted temperature management at $33^{\circ} \mathrm{C}$ vs $36^{\circ} \mathrm{C}$ after out-of-hospital cardiac arrest: a randomized clinical trial. JAMA Neurol. 2015;72(6):634-41.

26. Sondag L, Ruijter BJ, Tjepkema-Cloostermans MC, Beishuizen A, Bosch FH, van Til JA, et al. Early EEG for outcome prediction of postanoxic coma: prospective cohort study with cost-minimization analysis. Crit Care. 2017;21(1):111.

27. Rossetti AO, Tovar Quiroga DF, Juan E, Novy J, White RD, Ben-Hamouda N, et al. Electroencephalography predicts poor and good outcomes after cardiac arrest: a two-center study. Crit Care Med. 2017;45(7):e674-82.

28. Streitberger $\mathrm{KJ}$, Leithner $\mathrm{C}$, Wattenberg $\mathrm{M}$, Tonner PH, Hasslacher J, Joannidis M, et al. Neuron-specific enolase predicts poor outcome after cardiac arrest and targeted temperature management: a multicenter study on 1,053 patients. Crit Care Med. 2017;45(7):1145-51.

\section{Ready to submit your research? Choose BMC and benefit from:}

- fast, convenient online submission

- thorough peer review by experienced researchers in your field

- rapid publication on acceptance

- support for research data, including large and complex data types

- gold Open Access which fosters wider collaboration and increased citations

- maximum visibility for your research: over $100 \mathrm{M}$ website views per year

At $\mathrm{BMC}$, research is always in progress.

Learn more biomedcentral.com/submissions 